\title{
TECHNICAL
}

\section{Non-destructive Rapid Determination of Radium-226 in Soil Using Radon-222 Escape-to-Production Ratio}

\author{
Toshio KataoKa, ${ }^{* * 1}$ Kenshuh MichihIro, ${ }^{* *, * 1}$ Hirokazu SugiYama, ${ }^{* * *, * 1}$ \\ Takashi Yamamoto, $* * * *, * 1$ and Eiji YUNOKI*****,*1
}

(Received September 12, 1986)

(Accepted November 22, 1986)

It is greatly desirable that ${ }^{226} \mathrm{Ra}$ in the environmental materials is rapidly determined for an accidental release. Radium-226 can be rapidly determined by being coprecipitated with barium sulphate. But, this method requires complicated chemical treatments.

We derived the formula for rapid determination of ${ }^{226} \mathrm{Ra}$ in soil by gamma-ray spectrometry in consideration of ${ }^{222} \mathrm{Rn}$ escape-to-production ratio of soil. Using this formula, ${ }^{226} \mathrm{Ra}$ in soil could be determined within 2 days.

Furthermore, ${ }^{226} \mathrm{Ra}$ content in the river-bed soil (weathered granitic rock) around Ningyoh-Tohge was almost the same level of that in the granitic rock in Japan. And, ${ }^{222} \mathrm{Rn}$ escape-to-production ratios and ${ }^{226} \mathrm{Ra}$ contents of the paddy, upland and virgin soils around Ningyoh-Tohge, which are volcanic ash, were in agreement with those of other volcanic ash soils.

KEY WORDS: non-destructive rapid determination, radium-226, radon-222 escape-to-production ratio, uranium mine, river-bed soil, paddy soil, upland soil, water content by weight

\section{INTRODUCTION}

It is well known that ${ }^{226} \mathrm{Ra}$ produced by the decays of ${ }^{238} \mathrm{U}$ and other members of the ${ }^{238} \mathrm{U}$ series is more contained in river water around uranium mine than in commonly encountered river water. Radium-226 contents in the environmental materials such as river water and river-bed soil have been measured as well as ${ }^{238} \mathrm{U}$ contents for monitoring around uranium mine, ${ }^{1-4}$ ) since ${ }^{226} \mathrm{Ra}$ is the most radiotoxic. Therefore, it is greatly desirable that ${ }^{226} \mathrm{Ra}$ is rapidly determined to detect accidental release and to estimate

* 片岡敏夫, ${ }^{* *}$ 道広憲秀, ${ }^{* * *}$ 杉山広和, $* * * *$ 山本隆志,

$* * * * *$ 柚木英二

*1 Institute of Environment and Public Health of Okayama Prefecture; 739-1, Uchio, Okayama-shi 701-02, Japan.

岡山県環境保健センター保健科学部理学科; 岡山市内尾 739-1 (†701-02)

Institute of Environment and Public Health of Okayama Prefecture; 1-739, Uchio, Okayama 70102, Japan. internal dose of person living there.

In the previous paper, ${ }^{5}$ ) we described the rapid determination of ${ }^{226} \mathrm{Ra}$ in soil by ${ }^{224} \mathrm{Ra}$ correction for a conventional WHO method. The method requires complicated chemical treatments. On the contrary, the gamma-ray spectrometry ${ }^{6-8)}$ does not demand the chemical treatment in order to determine ${ }^{226} \mathrm{Ra}$ in the soil. About 1 month is required until ${ }^{214} \mathrm{~Pb}$ and ${ }^{214} \mathrm{Bi}$ reach secular equilibrium with ${ }^{225} \mathrm{Ra}$ after sealing, since ${ }^{214} \mathrm{~Pb}$ and ${ }^{214} \mathrm{Bi}$ that emit gamma-rays are used for determination of ${ }^{226} \mathrm{Ra}$.

We describe non-destructive rapid determination of ${ }^{226} \mathrm{Ra}$ in the soil using $\mathrm{Ge}(\mathrm{Li})$ detector, in consideration of ${ }^{222} \mathrm{Rn}$ that is ${ }^{226} \mathrm{Ra}$ daughter and ${ }^{214} \mathrm{~Pb}$ and ${ }^{214} \mathrm{Bi}$ precursor. Furthermore, the ${ }^{222} \mathrm{Rn}$ escape-to-production ratios and ${ }^{226} \mathrm{Ra}$ contents of paddy, upland and virgin soils around NingyohTohge are evaluated.

\section{EXPERIMENTAL}

River-bed soil (weathered granitic rock) was 
sampled at Ikegoh River near Ningyoh-Tohge $\left(35^{\circ} 18^{\prime} \mathrm{N}, 133^{\circ} 35^{\prime} \mathrm{E}\right)$ for the present study. The fresh soil (water content by weight: $10.9 \%, 15.0 \%$ and $17.2 \%$ ), the air-dried soil (water content by weight: $0.98 \%, 6.59 \%$ and $8.7 \%$ ) and the soil dried with a drying kiln (water content by weight: $0 \%$ ) were prepared for measurement. About 1.3 $\mathrm{kg}$ of the soil sample was placed in a $0.5 \mathrm{~cm}$ thickwalled acrylic capsule $19 \mathrm{~cm}$ in diameter and 5 $\mathrm{cm}$ high. The capsule was sealed with araldite after removing soil air by a vacuum pump and returning to atmospheric pressure with the air. After letting the capsule alone for about $8 \mathrm{~h}$ to allow the short-lived ${ }^{222} \mathrm{Rn}$ daughters which retained at the time of sealing to decay, the measurement of the soil sample was made with a 75 $\mathrm{cm}^{3} \mathrm{Ge}(\mathrm{Li})$ detector (the first measurement). The soil sample was measured with the same detector and in the same geometry as the first measurement about 30 days after sealing to allow seclar equilibrium to be established between ${ }^{226} \mathrm{Ra}$ and its short-lived daughters (the second measurement). The counting times of both measurements were $80,000 \mathrm{~s}$. For the paddy, upland and virgin soils around Ningyoh-Tohge (volcanic ash soils), which are the fresh soils, the same measurements were made.

The ${ }^{226} \mathrm{Ra}$ standard consists of $5.58 \mathrm{~g}$ of a pitchblende sample supplied by NBL (the New Brunswick Laboratory of the Atomic Energy Commission, New Brunswick, New Jersey) mixed with disodium hydrogenphosphate, anhydrous $\left(\mathrm{Na}_{2} \mathrm{HPO}_{4}\right)$. And, $\mathrm{Na}_{2} \mathrm{HPO}_{4}$ was used as the soil blank. The counting times of the ${ }^{226} \mathrm{Ra}$ standard and the soil blank were $10,000 \mathrm{~s}$ and $80,000 \mathrm{~s}$, respectively.

\section{CALCULATION}

\section{1. ${ }^{222} \mathrm{Rn}$ escape-to-production ratio of soil}

The net peak area count of the interesting gamma-ray of the soil sample for the first measurement, $P_{1}$ (counts) is represented by

$$
\begin{aligned}
P_{1}= & \varepsilon I A_{\mathrm{epr}} W_{\mathrm{epr}}\left(1-\frac{\omega_{\mathrm{epr}}}{100}\right) \\
& \left\{(1-\delta)\left(T_{2}-T_{1}\right)+\delta \int_{T_{1}}^{T_{2}} f(t) \mathrm{d} t\right\},
\end{aligned}
$$

and the net peak area count of the interesting gamma-ray of the soil sample for the second measurement, $P_{2}$ (counts) is represented by

$$
P_{2}=\varepsilon I A_{\mathrm{epr}} W_{\mathrm{epr}}\left(1-\frac{\omega_{\mathrm{epr}}}{100}\right) T,
$$

where $\varepsilon$ is absolute peak detection efficiency of the $\mathrm{Ge}(\mathrm{Li})$ detector for the interesting gamma-ray; $I$ is branching ratio of the interesting gamma-ray of ${ }^{214} \mathrm{~Pb}$ and/or ${ }^{214} \mathrm{Bi} ; A_{\text {epr }}, W_{\text {epr }}$ and $\omega_{\mathrm{epr}}$ are ${ }^{226} \mathrm{Ra}$ content in the soil sample $\left(\mathrm{Bq} \cdot \mathrm{g}^{-1}\right.$ of dry soil), weight of the soil sample (g) and water content by weight of the soil sample $(\%)$ for the evaluation of the ${ }^{222} \mathrm{Rn}$ escapeto-production ratio, respectively; $\delta$ is ${ }^{222} \mathrm{Rn}$ escapeto-production ratio of the soil; $T_{1}$ is time interval from the sealing to the start of the first measurement (s); $T_{2}$ is time interval from the sealing to the end of the first measurement (s); $T$ is measuring time of the second measurement $(\mathrm{s}) ; f(t)$ is ingrowth factor of ${ }^{214} \mathrm{~Pb}$ and/or ${ }^{214} \mathrm{Bi}$ by using BATEMAN's equations and neglecting the terms which have small contributions. $\int_{T_{1}}^{T_{2}} f(t) \mathrm{d} t$ for ${ }^{214} \mathrm{~Pb}$ and ${ }^{214} \mathrm{Bi}$ are represented by the following equation, respectively.

$$
\begin{aligned}
{ }^{214} \mathrm{~Pb}: \int_{T_{1}}^{T_{2}} f(t) \mathrm{d} t= & T_{2}-T_{1}+\frac{1}{\lambda_{2}}\left\{\exp \left(-\lambda_{2} T_{2}\right)-\exp \left(-\lambda_{2} T_{1}\right)\right\}+\frac{\lambda_{2} \lambda_{4}}{\lambda_{3}{ }^{2}\left(\lambda_{4}-\lambda_{3}\right)}\left\{\exp \left(-\lambda_{3} T_{2}\right)-\exp \left(-\lambda_{3} T_{1}\right)\right\} \\
& -\frac{\lambda_{2} \lambda_{3}}{\lambda_{4}{ }^{2}\left(\lambda_{3}-\lambda_{4}\right)}\left\{\exp \left(-\lambda_{4} T_{2}\right)-\exp \left(-\lambda_{4} T_{1}\right)\right\}, \\
{ }^{214} \mathrm{Bi}: \int_{T_{1}}^{T_{2}} f(t) \mathrm{d} t= & T_{2}-T_{1}+\frac{1}{\lambda_{2}}\left\{\exp \left(-\lambda_{2} T_{2}\right)-\exp \left(-\lambda_{2} T_{1}\right)\right\}-\frac{\lambda_{2} \lambda_{4} \lambda_{5}}{\lambda_{3}{ }^{2}\left(\lambda_{4}-\lambda_{3}\right)\left(\lambda_{5}-\lambda_{3}\right)} \\
& \times\left\{\exp \left(-\lambda_{3} T_{2}\right)-\exp \left(-\lambda_{3} T_{1}\right)\right\}-\frac{\lambda_{2} \lambda_{3} \lambda_{5}}{\lambda_{4}{ }^{2}\left(\lambda_{3}-\lambda_{4}\right)\left(\lambda_{5}-\lambda_{4}\right)}\left\{\exp \left(-\lambda_{4} T_{2}\right)-\exp \left(-\lambda_{4} T_{1}\right)\right\} \\
& -\frac{\lambda_{2} \lambda_{3} \lambda_{4}}{\lambda_{5}{ }^{2}\left(\lambda_{3}-\lambda_{5}\right)\left(\lambda_{4}-\lambda_{5}\right)}\left\{\exp \left(-\lambda_{5} T_{2}\right)-\exp \left(-\lambda_{5} T_{1}\right)\right\},
\end{aligned}
$$


where $\lambda_{1}$ is decay constant for ${ }^{226} \mathrm{Ra}\left(\mathrm{s}^{-1}\right) ; \lambda_{2}$ for ${ }^{222} \mathrm{Rn}\left(\mathrm{s}^{-1}\right) ; \lambda_{3}$ for ${ }^{218} \mathrm{Po}\left(\mathrm{s}^{-1}\right) ; \lambda_{4}$ for ${ }^{214} \mathrm{Po}\left(\mathrm{s}^{-1}\right)$; $\lambda_{5}$ for ${ }^{214} \mathrm{Bi}\left(\mathrm{s}^{-1}\right)$.

From Eqs. (1) and (2), the ${ }^{222} \mathrm{Rn}$ escape-toproduction ratio of the soil is given by

$$
\delta=\frac{P_{2}\left(T_{2}-T_{1}\right)-P_{1} T}{P_{2}\left\{T_{2}-T_{1}-\int_{T_{1}}^{T_{2}} f(t) \mathrm{d} t\right\}} .
$$

In the case of $T=T_{2}-T_{1}$, Eq. (5) is rewritten by

$$
\begin{gathered}
\delta=\frac{\left(P_{2}-P_{1}\right) T}{P_{2}\left\{T-\int_{T_{1}}^{T_{2}} f(t) \mathrm{d} t\right\}} . \quad \text { (6) } \begin{array}{l}
\text { escape-to-production ratio of the } \\
\text { content in the soil sample, } A_{\mathrm{sa}} \\
\text { soil }) \text { is represented by }
\end{array} \\
A_{\mathrm{sa}}=\frac{P_{\mathrm{sa}} A_{\mathrm{st}, \mathrm{t}} T_{\mathrm{st}}}{\left(1-\frac{\omega}{100}\right) W_{\mathrm{sa}} P_{\mathrm{st}}\left[T_{\mathrm{sa}, 2} T_{\mathrm{sa}, 1}-\bar{\delta}\left\{T_{\mathrm{sa}, 2}-T_{\mathrm{sa}, 1}-\int_{T_{\mathrm{sa}, 1}}^{T_{\mathrm{sa}, 2}} f(t) \mathrm{d} t\right\}\right],}
\end{gathered}
$$

2. Radium-226 content in soil

The soil sample has been measured about 1 month after sealing and ${ }^{226} \mathrm{Ra}$ content in the soil has been obtained by comparing the net peak area count of interesting gamma-ray with that of standard $^{6-8)}$ (conventional method). This method requires about 1 month for obtaining results.

Now, we derive the equation for rapid determination of ${ }^{226} \mathrm{Ra}$ in the soil using the ${ }^{222} \mathrm{Rn}$ escape-to-production ratio of the soil. The ${ }^{226} \mathrm{Ra}$ content in the soil sample, $A_{\mathrm{sa}}\left(\mathrm{Bq} \cdot \mathrm{g}^{-1}\right.$ of dry

where $P_{\mathrm{sa}}$ is net peak area count of the interesting gamma-ray of the soil sample (counts); $A_{\mathrm{st}, \mathrm{t}}$ is total ${ }^{226} \mathrm{Ra}$ content in the ${ }^{226} \mathrm{Ra}$ standard $(\mathrm{Bq})$; $T_{\text {st }}$ is counting time of the ${ }^{226} \mathrm{Ra}$ standard (s); $P_{\text {st }}$ is net peak area count of the interesting gamma-ray of the ${ }^{226} \mathrm{Ra}$ standard (counts); $\omega$ is water content by weight of the soil sample $(\%) ; W_{\mathrm{sa}}$ is weight of the soil sample for the measurement $(\mathrm{g})$; $\bar{\delta}$ is average value of the ${ }^{222} \mathrm{Rn}$ escape-to-production ratio of the same soil as the sample; $\boldsymbol{T}_{\mathrm{sa}, 1}$ is time interval from the sealing to the start of the measurement (s); $T_{\mathrm{sa}, 2}$ is time interval from the sealing to the end of the measurement (s). The preparation and the measurement of the soil sample are the same methods as "the first measurement."

\section{RESULTS AND DISCUSSION}

Figure 1 shows ${ }^{222} \mathrm{Rn}$ escape-to-production ratio of the soil calculated by Eq. (6). The ${ }^{222} \mathrm{Rn}$ escape-to-production ratios obtained using the net peak area counts of $352 \mathrm{keV}{ }^{214} \mathrm{~Pb}$ gamma-rays and $609 \mathrm{keV}{ }^{214} \mathrm{Bi}$ gamma-rays are in fairly good agreement. The ${ }^{222} \mathrm{Rn}$ escape-to-production ratio of the soil does not depend on the water content by weight, but that of the diluvial soil decreases under $3 \%$ of water content by weight. ${ }^{8)}$ It is thought that this difference is due to the nature of the soils.

The ${ }^{226} \mathrm{Ra}$ contents in the dry soils evaluated by the conventional method are shown in Fig. 2 . They do not depend on the water content by weight naturally. Uranium-238 content in the granitic rock in Japan ranges from 11.1 to 111 $\mathrm{mBq} \cdot \mathrm{g}^{-1}{ }^{10,11)}$ with a few exceptions. ${ }^{7,9)}$ It is presumed that ${ }^{226} \mathrm{Ra}$ content in the granitic rock in Japan is the same range as ${ }^{238} \mathrm{U}$ content, even if there is a little deviation of the secular equilibrium between ${ }^{238} \mathrm{U}$ and ${ }^{226} \mathrm{Ra}$. Therefore, the ${ }^{226} \mathrm{Ra}$ content of this river-bed soil may be within the above mentioned range.

The average value of the ${ }^{222} \mathrm{Rn}$ escape-to-production ratio of the river-bed soil (weathered granitic rock), $\bar{\delta}$ is $0.506 \pm 0.013\left({ }^{214} \mathrm{~Pb}, 352 \mathrm{keV}\right)$ and/or $0.528 \pm 0.006\left({ }^{214} \mathrm{Bi}, 609 \mathrm{keV}\right)$. For riverbed soil (weathered granitic rock) at the about 1 $\mathrm{km}$ upstream point, ${ }^{226} \mathrm{Ra}$ determined using the net peak area count of the first measurement, the value of $\bar{\delta}$ and Eq. (7). The result is shown in Table 1. Radium-226 in the same sample determined by the conventional method is also shown in the table for comparison. They are in good

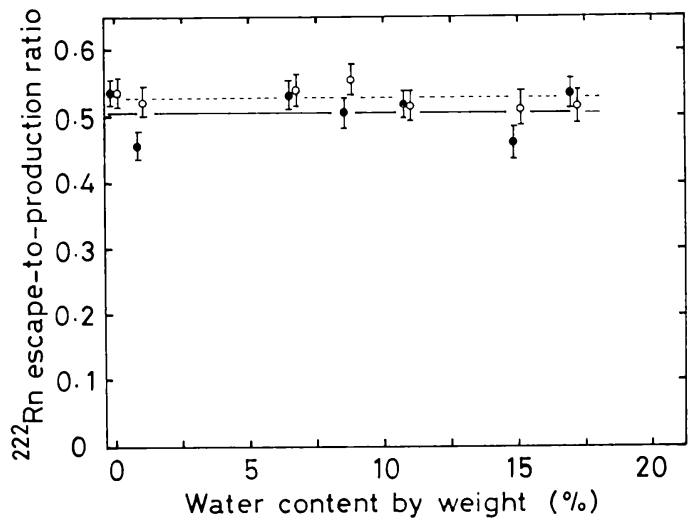

Fig. 1 Relation between ${ }^{222} \mathrm{Rn}$ escape-to-production ratio of river-bed soil and water content by weight. : using $352 \mathrm{keV}{ }^{214} \mathrm{~Pb}$ gamma-ray; $\mathrm{O}$ : using $609 \mathrm{keV}{ }^{214} \mathrm{Bi}$ gamma-ray. 


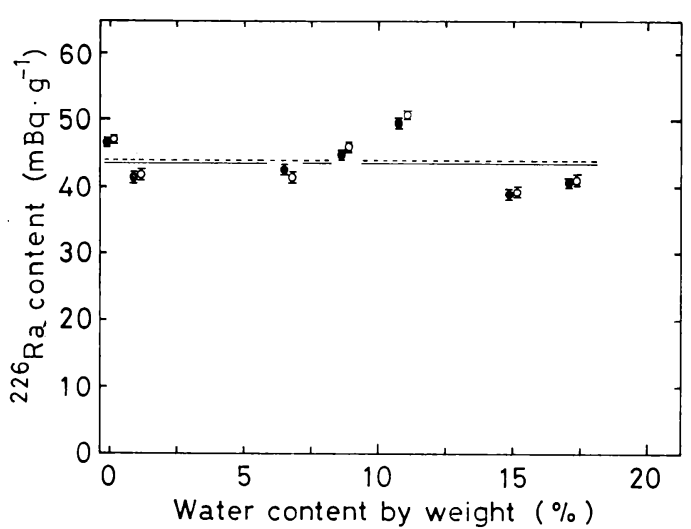

Fig. 2 Relation between ${ }^{22 i} \mathrm{Ra}$ content in the river-bed soil and water content by weight. - : using $352 \mathrm{keV}{ }^{214} \mathrm{~Pb}$ gamma-ray; $\bigcirc$ : using $609 \mathrm{keV}{ }^{214} \mathrm{Bi}$ gamma-ray.

Table 1 A comparison of the present method with the conventional method.

\begin{tabular}{lcc}
\hline Gamma-ray & ${ }^{226} \mathrm{Ra}$ content $\left(\mathrm{mBq} \cdot \mathrm{g}^{-1}\right.$ of dry soil $)$ \\
\cline { 2 - 3 } & Present method & $\begin{array}{c}\text { Conventional } \\
\text { method }\end{array}$ \\
\hline $\begin{array}{l}{ }^{214} \mathrm{~Pb} \\
352 \mathrm{keV}\end{array}$ & $28.5 \pm 1.3$ & $30.2 \pm 0.6$ \\
${ }^{214} \mathrm{Bi}$ & $29.3 \pm 1.2$ & $32.2 \pm 0.7$ \\
$609 \mathrm{keV}$ & & \\
\hline
\end{tabular}

agreement. This suggests that ${ }^{226} \mathrm{Ra}$ in the soil can be determined within 2 days, when the ${ }^{222} \mathrm{Rn}$ escape-to-production ratio of the sample is known. As there is the case that ${ }^{22} \mathrm{Rn}$ escape-to-production ratio of the soil decreases under $3 \%$ of water content by weight, ${ }^{8)}$ the fresh soil must be used as the sample.

It is necessary to evaluate the ${ }^{222} \mathrm{Rn}$ escape-toproduction ratios and ${ }^{226} \mathrm{Ra}$ contents of the paddy and upland soils, since the river water containing the drainage from the uranium mine is used for irrigation around the uranium mine. Thus, the ${ }^{222} \mathrm{Rn}$ escape-to-production ratios and ${ }^{226} \mathrm{Ra}$ contents of the paddy, upland and virgin soils (volcanic ash soils), which are fresh soils, are also measured. The results are shown in Table 2. They agree approximately with those of other volcanic ash soils. ${ }^{12,13)}$

\section{CONCLUDING REMARKS}

From this treatment, it is clearly demonstrated that the gamma-ray spectrometry in consideration of the ${ }^{222} \mathrm{Rn}$ escape-to-production ratio of the soil made the determination of ${ }^{226} \mathrm{Ra}$ in the soil within 2 days possible. So, this method is useful for monitoring ${ }^{226} \mathrm{Ra}$ in the soil in an early stage, when the accidental release of ${ }^{225} \mathrm{Ra}$ happens.

Furthermore, ${ }^{226} \mathrm{Ra}$ content in the river-bed soil (weathered granitic rock) around NingyohTohge is within the range of that in the granitic rock in Japan. And, the ${ }^{222} \mathrm{Rn}$ escape-to-production ratios and ${ }^{226} \mathrm{Ra}$ contents of the paddy, upland and virgin soils around Ningyoh-Tohge, which are volcanic ash, agree approximately with those of other volcanic ash soils.

ACKNOWLEDGEMENT: The authors are indebted to the staff of Japan Chemical Analysis Center for providing a standard pitchblende sample supplied by NBL.

\section{REFERENCES}

1) A. C. Paul, V.S. Londhe and K.C. Pillai; Natural Radiation Environment (III) (ed. by T.F. Gesell and W.M. LowDER), USDOE Report CONF-780422, Vol. 2, p. 1633 (1980).

2) P.M. Markose, K.P. Eppen, S. Venkataraman and P.R. KAMATH; Natural Radiation Environment (III) (ed. by T.F. Gesell and W.M. LowDER), USDOE Report CONF-780422, Vol. 2, p. 1655 (1980).

3) F. Sebesta, P. Bones, J. Sedlacek, J. John and

Table $2{ }^{222} \mathrm{Rn}$ escape-to-production ratio and ${ }^{226} \mathrm{Ra}$ content of soil. Only one sample was measured respectively.

\begin{tabular}{|c|c|c|c|c|c|}
\hline \multirow{2}{*}{ Sample name } & \multirow{2}{*}{$\begin{array}{l}\text { Water content } \\
\text { by weight }(\%)\end{array}$} & \multicolumn{2}{|c|}{${ }^{222} \mathrm{Rn}$ escape-to-production ratio } & \multicolumn{2}{|c|}{${ }^{226} \mathrm{Ra}$ content $\left(\mathrm{mBq} \cdot \mathrm{g}^{-1}\right.$ of dry soil) } \\
\hline & & ${ }^{214} \mathrm{~Pb}, 352 \mathrm{keV}$ & ${ }^{214} \mathrm{Bi}, 609 \mathrm{keV}$ & ${ }^{214} \mathrm{~Pb}, 352 \mathrm{keV}$ & ${ }^{214} \mathrm{Bi}, 609 \mathrm{keV}$ \\
\hline Paddy soil & 60.1 & $0.352 \pm 0.035$ & $0.417 \pm 0.035$ & $34.5 \pm 0.78$ & $36.4 \pm 0.85$ \\
\hline Upland soil & 21.3 & $0.443 \pm 0.030$ & $0.421 \pm 0.033$ & $34.9 \pm 0.70$ & $33.6 \pm 0.78$ \\
\hline Virgin soil & 159 & $0.393 \pm 0.049$ & $0.493 \pm 0.054$ & $38.5 \pm 1.1$ & $37.0 \pm 1.1$ \\
\hline
\end{tabular}


R. SANDRIK; Environ. Sci. Technol., 15, 71 (1981).

4) International Atomic Enegry Agency; The Behavior of Radium in Waterways and Aquifers, IAEA-TEDOC-301 (1984).

5) T. Kataoka, K. Michiniro and T. Yamamoto; Radioisotopes, 34, 662 (1985).

6) P.F. Gustafson and S.S. Brar; "The Natural Radiation Environment" (ed. by J.A.S. AdAMS and W.M. LowDER), p. 466 (1964), Univ. of Chicago Press, Chicago.

7) K. Miegumi and T. Mamuro; Hoken Butsuri, 12, 181 (1977).

8) T. KATAOKA and Y. IKebE; Hoken Butsuri, 15, 47 (1980).

9) K. Megumi and T. Mamuro; J. Geophys. Res., 82, 353 (1977).
10) H. KanAya and S. Ishihara; The Natural Radiation Environment (II) (ed. by J.A.S. AdAms, W.M. Lowder and T. Gesell), Userda Report CONF720805-P2, p. 517 (1974).

11) Y. Miyake, Y. Sugimura and Y. Hirano; The Natural Radiation Environment (II) (ed. by J.A.S. AdAms, W.M. Lowder and T. GeSELL), USERDA Report CONF-720805-P2, p. 535 (1974).

12) T. KataOKA and Y. IkeBE; J. Nucl. Sci. Technol., 19, 757 (1982).

13) P.M.C. Barretto, R.B. Clark and J.A.S. ADAms; The Natural Radiation Environment (II) (ed. by J.A.S. Adams, W.M. Lowder and T. GESSELL), USERDA Report CONF-720805P2, p. 731 (1974). 